\title{
CLASIFICACIÓN DE LOS PERSONAJES FEMENINOS EN LAS COMEDIAS DE ARISTÓFANES
}

\author{
Elisa Guevara Macías
}

\section{(c) $(7) \Theta$}

Doi: https://doi.org/10.15517/rfl.v46iEspecial.41632

URL: https://revistas.ucr.ac.cr/index.php/filyling/index 



\title{
CLASIFICACIÓN DE LOS PERSONAJES FEMENINOS EN LAS COMEDIAS DE ARISTÓFANES
}

\author{
FEMALE CHARACTERS CLASSIFICATION IN \\ ARISTOPHANIC COMEDY
}

\section{Elisa Guevara Macías}

\begin{abstract}
RESUMEN
En el presente artículo se clasifican todos los personajes femeninos de las comedias de Aristófanes, siguiendo las categorías expuestas por Luis Gil (1993; 2012). Se agrupan en personajes de carácter imitativo -de las figuras históricas reales o de origen mítico- y en personajes representativos, ya sean los inventados con una caracterización original, los tipificados de carácter genérico o las personificaciones con sentido alegórico. Seguidamente, de forma concisa, se analiza la invención de cada personaje, su función en la obra y su comicidad.

Palabras clave: dramatis personae; mujeres; Aristófanes; comedia griega; heroína cómica.
\end{abstract}

\begin{abstract}
In this paper, all female characters present in the Aristophanic comedies are classified following the categories exposed by Luis Gil $(1993,2012)$. They are grouped in imitative characters -of real historical figures or mythical origin-, and representative characters, whether invented with an original characterization, typified with generic categorization or made with personifications, which may have allegorical meaning. Next, the invention of each character, its function and comic interactions in the play are analyzed concisely.
\end{abstract}

Keywords: dramatis personae; women; Aristophanes; Greek Comedy; comic heroine.

\section{Introducción}

Los personajes en la Comedia Antigua fueron muy diversos y originales, si se comparan con los de la Comedia Nueva del siglo III a. C. No obstante, Aristófanes es el único autor de Comedia Antigua del cual se conservan obras en estado íntegro. En las once comedias conservadas, existe una gran variedad de personajes. A grandes rasgos, estos se diferencian por su sexo (mujer o hombre), por su edad (joven o anciano), por su condición social (libre o esclavo), por su naturaleza (humana, divina o animal).

Lic. Elisa Guevara Macías. Profesora de la Escuela de Filología, Lingüística y Literatura. Universidad de Costa Rica. Costa Rica. Correo electrónico: elisa.guevaramacias@ucr.ac.cr

Recepción: 20- 06- 19

Aceptación: 13- 11- 19 
Si bien, la mayoría son masculinos, Aristófanes ha creado personajes femeninos importantes $\mathrm{y}$, de hecho, es el primer comediógrafo antiguo en idear una heroína cómica ${ }^{1}$ con papel expresamente protagónico, como Lisístrata o Praxágoras. Únicamente en dos obras, Caballeros y Las Nubes, no aparecen personajes femeninos y son las obras con menor elenco, siete y seis dramatis personae respectivamente. De acuerdo con el listado de González Vázquez (2016, pp. 501-511), en el total de las obras conservadas hay aproximadamente 175 personajes, de los cuales 42 son femeninos, es decir, un $24 \%$. Siguiendo este listado, a continuación, en la Figura 1 se presenta un gráfico con la distribución de los personajes en cada comedia de Aristófanes clasificados en: hombres, mujeres, animales u otros, como las nubes.

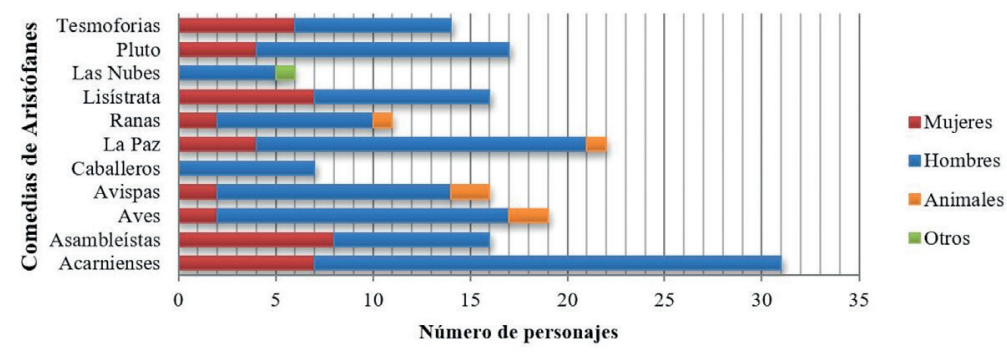

Figura 1. Distribución de los personajes en las comedias de Aristófanes

No obstante, en este listado se unifican personajes colectivos (flautistas, viejas, posaderas, mujeres, niños, etc.), por lo que en realidad la cantidad de personajes es mucho más alta. En este sentido, se identificaron 48 específicos en total y 4 colectivos, como los coros o grupos de personas de número indefinido.

Es interesante que obras como Lisístrata y Asambleístas, conocidas como comedias de mujeres, en realidad no cuentan con una mayoría de personajes femeninos, aunque sí tienen un coro y protagonista femeninos. Por su parte, las Tesmoforiantes no es propiamente una comedia de mujeres, pues, a pesar de que se desarrolla en un ambiente femenino, el protagonista es masculino.

El análisis de los personajes femeninos aristofánicos es un ámbito de las comedias que no ha sido estudiado de manera sistemática. Existen numerosos análisis sobre Lisístrata y Praxágoras, como heroínas cómicas y protagonistas. No obstante, aparte de ellas, hay otros personajes femeninos de carácter menor y de participación secundaria que tienen importancia en la comicidad y la estructura de las obras, pero, por lo general, no se han considerado. Por ello, el presente artículo busca realizar una clasificación de estos por medio de las categorías generales propuestas por Gil $(1993 ; 2012)$ según la invención de los dramatis personae en Aristófanes.

El autor expone dos clases de personajes: imitativos y representativos. La primera se basa en figuras existentes, las cuales son imitadas desde una perspectiva original. En el caso de los personajes representativos, estos son creados por el comediógrafo. En los imitativos hay dos tipos: las figuras históricas reales, generalmente contemporáneas al autor, y los personajes de origen mítico. En cuanto a los representativos, también hay dos tipos: los propiamente inventados y las personificaciones, las cuales pueden tener carácter alegórico. A partir de estas categorías, a continuación, se realiza una clasificación general de todos los personajes femeninos presentes en las comedias conservadas de Aristófanes.

1 Véanse López Férez (2006, p. 3) y Hughes (2012, p. 201). 


\section{Personajes imitativos}

En Aristófanes hay muchos ejemplos de personajes imitativos masculinos, pero, en el caso de los propiamente femeninos, no se conserva ninguno basado en una figura histórica real ni contemporánea al autor. Ello se debe posiblemente a la restringida posición social de las mujeres en la polis griega, pues no habría una mujer del contexto de Aristófanes lo suficientemente influyente como para ser objeto de injuria política en el teatro, como sí lo fueron Eurípides, Cleón, Lámaco o Agatón, figuras distinguidas en la Atenas del siglo V a. C..

En cuanto a los personajes míticos, únicamente hay un ejemplo femenino: Iris. Este personaje aparece en Las Aves y su papel es secundario. Una vez fundada Nephelokokkugía

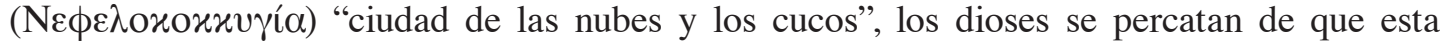
interfiere el libre tránsito de los sacrificios hechos por los hombres para ellos. Por esta razón, envían a Iris como mensajera, función tradicional de la diosa presente desde Homero $^{2}$.

Rumbo a la tierra, Iris es recibida de mala manera por Pistétero, anciano ateniense protagonista de la comedia Aves (2007c, v. 1200 ss.). La molestia de este radica en que la diosa ha traspasado las murallas de la utópica ciudad ${ }^{3}$. En el diálogo con Pistétero, la diosa interviene activamente 17 veces (vv. 1202-1261) hasta que finalmente es expulsada y se marcha profiriendo amenazas.

Este agón comienza con la presentación de la diosa (vv. 1199-1204): el anciano le pregunta de dónde viene y luego su nombre, a lo cual ella responde que del Olimpo y dice

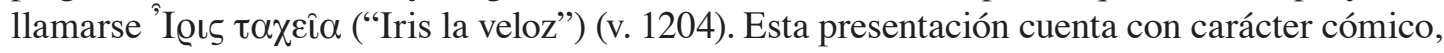
pues Pistétero la toma por una nave de guerra ( $\pi \lambda$ oîov) o por un casco de piel de perro ( $x$ vvî) (v. 1203), por lo que es vista como una amenaza. De hecho, el anciano le pregunta qué tipo de trirreme ateniense es: páralos o salaminia (v. 1204). Ambas son naves mensajeras, la primera se utilizaba generalmente para transportar delegaciones a fiestas y celebraciones de carácter público, mientras que la Salamina era célebre por llevar oficiales atenienses en busca de trasgresores que delinquieron en contra del estado, como con Alcibíades (Aristófanes, 2007c, p. 356, nota 20). La comicidad de esta mención radica en que Iris no entiende lo que Pistétero quiere decir.

Después de la presentación, continúa el ataque a la diosa por entrar a la ciudad

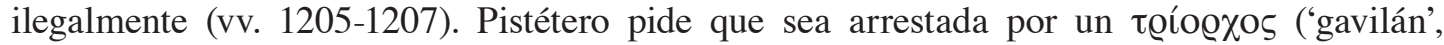
'halcón') que sería el guardia de la ciudad de las aves. Este término es un equívoco cómico con $\tau \rho ı ́ \rho \chi \eta \varsigma$ (tres-testículos) ${ }^{4}$. Macías Aparicio (Aristófanes, 2007c, p. 421, nota 107) sugiere que la alusión sexual se debe a la repentina visión de Iris como una hermosa joven.

En la interrogación sobre su llegada a la ciudad, se le pregunta por cuál puerta ha entrado y si ha realizado los trámites de ingreso (vv. 1205-1219). Finalmente, se confirma la "entrada ilegal" de la diosa (vv. 1217-1219) y esta es acusada por su delito (vv. 1220-1224). Pistétero afirma que el castigo será la muerte, pero la diosa aclara la imposibilidad del cumplimiento de

2 Ilíada (II, vv. 785-806; III, vv. 121-145; VIII, vv. 411-425; XII, vv. 181-210; XV, vv. 151-183; XVIII, vv. 165-201; XXIII, vv. 201-225; XXIV, vv. 143-187). También tiene esta función en Eurípides (1985, Heracles, vv. 822-874), pero como mensajera de Hera.

3 Posiblemente, la diosa habría aparecido sobre la escena suspendida por medio de una polea, pues el corifeo pide atención y mirada atenta "porque se oye cerca el ruido del batir de alas de un dios en el cielo" (2007c, Aves, vv. 1196-1198).

$4 \quad$ Véanse Liddell y Scott (1996, p. 1821) y Yarza (1998, p. 1395). 


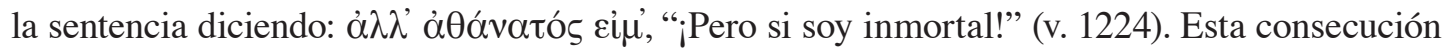
de absurdos trae consigo la intensificación paulatina de la comicidad del diálogo.

Al interpelarla sobre el motivo de su viaje, la diosa afirma ser mensajera de su padre, Zeus, para solicitar a los hombres que ofrezcan sacrificios a los dioses olímpicos (vv. 12291238). Aristófanes utiliza otra genealogía, pues tradicionalmente Iris es hija de Taumante y Electra (Hesíodo, 1978, Teogonía, vv. 266, 780). Siguiendo a Gil (2012, p. 72), Aristófanes crea novedosas genealogías míticas y les asigna atributos que tradicionalmente no les son propios. En el caso de Iris, en Aves, el autor sí utiliza sus rasgos tradicionales: "las veloces alas", atributo común con las aves, lo cual les da a estas la legitimidad como seres divinos (vv. 571-575).

Revelada la finalidad del viaje de Iris, Pistétero cuestiona su divinidad y la diosa sorprendida pregunta: “¿pues qué otros dioses existen?”, a lo cual el anciano explica que: “Los pájaros son ahora dioses para los hombres y a ellos han de ofrecerles los sacrificios y no a Zeus, por Zeus" (vv. 1236-1238). Aquí se observa la inversión propia de este mundo utópico, rematada con una interjección llena de ironía cómica. En este sentido, la incongruencia existente entre lo esperado por el público y lo representado intensifica la comicidad del diálogo, que llega a su punto más alto con la descarga de violencia verbal de las amenazas consiguientes.

En la amenaza de Iris (vv. 1239-1243), hay otro recurso cómico importante: la paratragedia, es decir, parodia no solo del contenido de tragedias concretas, sino del estilo de estas obras en general. En tono trágico, Iris amenaza a Pistétero con destrucción de la raza humana y recuerda posiblemente una escena de una tragedia titulada Licimnio, tal vez de Eurípides o quizás de Jenocles. En todo caso, se trata de una referencia oscura, pues en la actualidad se ha perdido el referente.

Ante esta amenaza, Pistétero la ataca virulentamente (vv. 1244-1256). Primero, afirma no atemorizarse con sus sandeces, en segundo lugar, desafía a Zeus y, en tercer lugar, agrede verbalmente a Iris. En esta última parte, se encuentra un ejemplo de humor sexual por medio de una amenaza de violación (vv. 1253-1256). La comicidad radica en la incongruecia, pues el anciano fanfarronea con cuestiones sexuales contra la diosa, la cual le responde iracunda con una maldición (v. 1257): “¡Así te mueras, desgraciado, por esas palabras!”. Por último, el anciano expulsa violentamente a Iris de la ciudad (vv. 1258-1261).

La comicidad de Iris se encuentra también en la distorsión mítica. De acuerdo con Gil (1993, p. 36), esta se logra cuando un personaje serio, como lo es una divinidad, se "reviste de una forma inferior e inapropiada a su categoría; se degrada lo sublime envolviéndolo en formas ridículas y burlescas". Ello se observa en el accionar y en el vocabulario de Iris, pues amenaza, insulta y maldice a Pistétero.

La irreverencia de Pistétero también desempeña un papel importante dentro de la comicidad de este diálogo. Este la amenaza repetidas veces (vv. 1220-1224, 1243-1255) y la ofende (vv. 1209, 1211), lo cual evidencia la inversión cómica que se desarrolla y se completa con la mención de los nuevos dioses: las Aves (vv. 1237-1238), así como también su superioridad frente a los dioses tradicionales (vv. 1225-1229). Esta Iris representa un claro ejemplo de la imitación cómica de un personaje mítico, para la cual se utiliza la parodia, la distorción mítica y la inversión.

\section{Personajes representativos}

En cuanto a los personajes representativos, hay dos tipos: los propiamente inventados y los creados a partir de la personificación. Los primeros se refieren a aquellos ideados por el 
comediógrafo de manera original. Siguiendo a Gil (1993, p. 34), estos personajes comúnmente tienen 'nombres parlantes' para describir su carácter o su accionar en la comedia.

Los personajes inventados por Aristófanes presentan diferencias de acuerdo a su invención, por ello, aquí se propone una separación: personajes de caracterización específica que comúnmente tienen un rol más activo en la acción y personajes genéricos que corresponden a un tipo cómico. Se debe hacer la salvedad de que estos últimos no son 'personajes tipo', como en la Comedia Nueva, sino que construyen su comicidad a partir de estereotipos que marcan su personalidad, forma de hablar u otras características. En el caso de Aristófanes, se observan algunos personajes "genéricos" que frecuentemente carecen de nombre y corresponden a tipos cómicos como la hija, esposa, anciana, esclava, etcétera. En general, son fácilmente reconocibles por el público, pues están "basados en la diversidad de mentalidades según el origen étnico, la clase social o la profesión” (Gil, 1993, p. 34).

En el caso de los personajes creados por personificación, estos consisten "en hacer hablar a un objeto mudo o a una idea abstracta y atribuirle una forma y un lenguaje acorde con su carácter o algún tipo de actividad" (Retórica a Herenio, 1997, p. 309). Gil (2012, p. 70) aclara que las personificaciones en Aristófanes no solamente incluyen ideas abstractas y objetos, sino también animales, como ocurre con los coros de algunas de sus obras, por ejemplo, las Ranas y las Aves. Siguiendo a Gil (2012), las personificaciones tienen tres modalidades: la animación, la antropomorfización y la edificación.

La animación consiste en conferir a un objeto inanimado una acción con independencia de su naturaleza: por ejemplo, los carbones del Parnes que asumen particularidades de los seres humanos, o las trirremes que en represalia devoran las higueras. La antropomorfización confiere a un objeto inanimado, a un animal, o a una noción abstracta, vida, actividad, apariencia, razón o sentimientos humanos: en Los acarnienses 724, unas correas de cuero son nombradas aguaciles del ágora y en Las avispas se ponen como testigos los cacharros de cocina. La deificación consiste en asignar la forma o los atributos propios de un ser divino a una idea abstracta (p. ej., Pólemos, Eirene), a un fenómeno físico (las nubes) o a un ser humano (Anfíteo) (Gil, 2012, p. 72).

Las personificaciones deificadas en Aristófanes son muy utilizadas. Komornicka (1964), citada por Gil (2012, p. 72), señala que una variante de las personificaciones son los "personajes alegóricos", los cuales son más complejos pues se basan en "metáforas continuadas", a fin de dar a entender una cosa expresando otra diferente. Ello ocurre por lo general con estas personificaciones deificadas. De hecho, Gil (1993, p. 35) explica que Aristófanes prefiere crear sus propios personajes divinos por medio de este recurso antes que emplear dioses del repertorio mitológico tradicional.

De acuerdo con Zimmermann (2014, p. 148) y Gil (2012, p. 72), en Aristófanes hay dos tipos de personificaciones deificadas: las figuras simbólicas mudas (mute symbolic figures) y las figuras parlantes, que son aquellas personificaciones que participan activamente en la acción dramática ${ }^{5}$.

Concluida la exposición de las características de cada clase de personajes representativos, seguidamente, se exponen los diferentes personajes femeninos inventados con caracterización específica y genérica, para después pasar a la exposición de las personificaciones.

5 Figuras mudas: Diallagé en Lisístrata; Spondaí en Los caballeros; Eirene, Opora y Theoría en La Paz; Basileia en Las aves. Figuras parlantes: Pólemos y Kydoimos en La paz; Díkaios Logos y Ádikos Logos en Las nubes; Penía y Ploutos en Pluto (Gil, 2012, p. 72; Zimmermann, 2014, p. 148). 


\subsection{Personajes inventados con caracterización específica}

Se encuentran siete personajes femeninos de caracterización específica en Aristófanes, los cuales corresponden a las comedias de mujeres o de ambiente femenino. En primer lugar, Lisístrata con cuatro personajes todas con nombres parlantes: Lísistrata, Cleonica o Calonica, Lampitó y Mirrina; después, Tesmoforiantes con Crítila y Mirtia, y finalmente, Asambleístas con Praxágora.

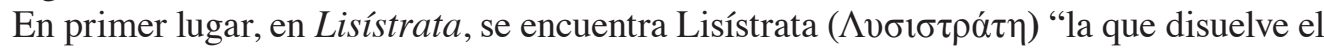

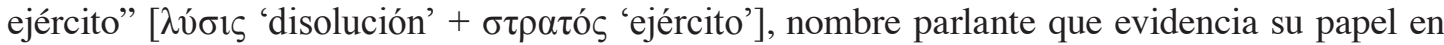
la obra. Interviene aproximadamente en 143 ocaciones a lo largo de toda la obra y su nombre es mencionado diez veces (2007e, vv. 6, 21, 69, 189, 216, 746, 1086, 1103, 1105, 1145). Al ser la protagonista un personaje serio, su comicidad radica en la inversión, pues adquiere un papel socialmente activo en el ámbito de lo público, espacio propiamente masculino. Su seriedad contrasta con el carácter de sus compañeras, definidas desde un principio como lascivas, adictas al sexo y al vino.

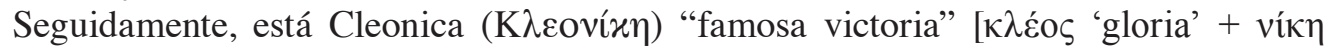

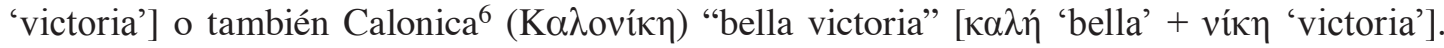
Participa activamente en el diálogo en 58 ocasiones y su nombre es mencionado dos veces (vv. $6,9)$. Este personaje anuncia desde la primera escena la victoria de la huelga sexual propuesta por Lisístrata para lograr el fin de la guerra.

En tercer lugar, se halla Lampitó ( $\Lambda \alpha \mu \pi \tau \omega ́)$ "la espléndida" [ $\lambda \alpha \dot{\alpha} \mu \pi \omega$ "brillar'], llamada así por su imponente físico, propio del estereotipo de la atlética espartana. Se trata de un uso intencional de la onomástica para, de manera metafórica, resaltar cómo la belleza física de la joven llama la atención del espectador. De hecho, en la obra se señala que logra un trasero firme gracias a que hace gimnasia y levanta "los pies hasta la altura del culo" (v. 82). Su comicidad reside en la representación de este esteriotipo y en su objetivación sexual por su misma belleza y juventud a manos de sus compañeras. Asimismo, en este personaje se puede encontrar características de humor lingüístico, pues habla en dialecto laconio, por lo que Aristófanes refleja la pronunciación de la dental aspirada como silbante, como ocurre con todos los personajes procedentes de la region de Laconia (Hernández Muñoz, 2016, p. 285). De hecho, Lampitó es la representante de las mujeres espartanas, cómplice de Lisístrata. Como tal, interviene 17 veces en diálogo y su nombre se menciona en siete ocasiones (vv. 77, 78, 181, 209, 242, 696, 998).

En cuarto lugar, se encuentra Mirrina (Mvg@ívๆ), cuyo nombre es un diminutivo

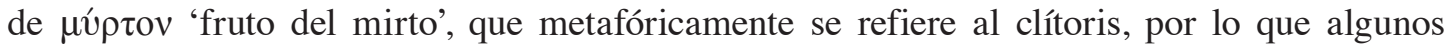
la traducen como "Clitorita" o "Chochito" (Hernández Muñoz, 2016, p. 331). Se trata de un nombre parlante que remite al papel del personaje en la obra, especialmente a la burla que

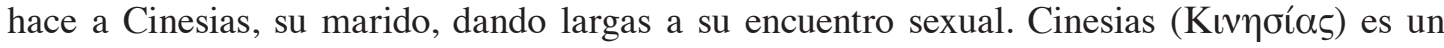
nombre derivado del verbo xıvé( 'mover', por lo que alude al moviemieno sexual. De hecho, Hernández Muñoz (2016, p. 331) sugiere que puede traducirse como "Follador". Este nombre parlante irónicamente ejemplifica la desdichada situación del personaje masculino, que en estado de continua erección suplica, al lado de su pobre hijo, el regreso de su esposa (v. 869 ss). No obstante, es engañado por ella, pues lo tienta repetidas veces sin concretar el acto sexual. Finalmente, el personaje sale de escena más excitado que antes y, por ende, con mayor interés

6 Existen vacilaciones en la transcripción del nombre (Hernández Muñoz, 2016, p. 85). 
por conseguir la paz con sus enemigos espartanos. Mirrina es el tercer personaje secundario femenino que más participa en la obra después de Lisístrata y Cleónice, pues interviene 47 veces y es mencionada en 6 momentos (vv. 70, 850, 851, 872, 874, 906).

En el caso de las Tesmoforiantes, se hallan dos personajes secundarios que participan

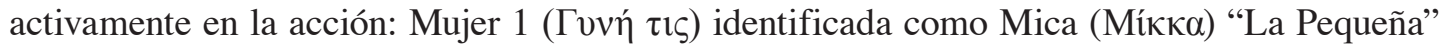

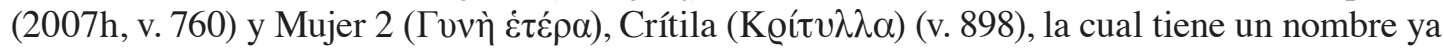
conocido en la comedia, pues en Lisístrata (2007e, v. 322) es utilizado para denominar a una de las integrantes del coro. Los nombres de estos dos personajes femeninos no revelan gran información sobre su participación en la obra.

Mica es definida como adicta al vino, tópico que nuevamente vuelve a aparecer para caracterizar a las mujeres. La escena cuenta con amplia comicidad, pues Mica lleva disfrazado un odre de vino como su bebé para poder embriagarse libremente en la festividad religiosa. Finalmente, su bebé es "degollado" por Mnesíloco, el pariente de Eurípides y esta trata de recoger su 'sangre', para que no se desperdicie. Su participación es relevante, ya que interviene 42 veces en esta escena cómica, en la cual ilustra la tipificación de la mujer aficionada al vino.

Por su parte, Crítila es un personajes serio, que participa relativamente poco en la acción, únicamente 16 veces. Según explica, se trata de una viuda con cinco hijos que se dedica a vender coronas como ofrendas a los dioses, pero que sufre penurias económicas porque sus ventas han disminuido a causa de Eurípides y su propagación del ateísmo y la crítica a los dioses extendida en sus tragedias. Por ello, es una de las mayores antagonistas del héroe cómico. Su sencillez contrasta con el lenguaje trágico de la simulación paródica de Mnesícolo y de Eurípides. Crítila no entiende este lenguaje y confunde personajes míticos. En su ignorancia radica su comicidad, pues Crítila en todo momento se mantiene en el mundo real y cotidiano en contraste con la parodia trágica montada por los personajes masculinos.

En el caso de las Asambleístas, el único personaje femenino de caracterización específica es la protagonista Praxágora (П $\rho \xi \alpha \gamma o ́ \rho \alpha)$, cuyo nombre se menciona tres veces (2007d, vv. 129, 241, 520). Se trata también de un nombre parlante, compuesto de la raíz $\pi \varrho \alpha \xi$ -

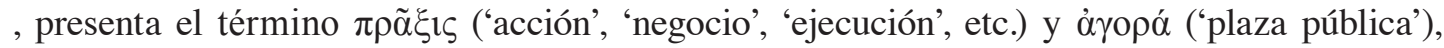
evidenciando su papel en la obra, pues puede ser traducido ${ }^{7}$ como "la que actúa en el ágora" o "que habla con éxito". Al igual que Lisístrata, es la heroína cómica y, por ende, un personaje serio. Además, es el segundo personaje femenino con mayor participación después de Lisístrata, pues interviene en la acción aproximadamente en 102 ocasiones. Siguiendo a Macía Aparicio (Aristófanes, 2007e, p. 17), ambos personajes tienen varias características en común: ambas son mujeres probablemente en la treintena, es decir, ya maduras para la época, y se encuentran insatisfechas con la situación política, especialmente por el frecuente fracaso de los varones, por lo que deciden tomar partido en las decisiones de la ciudad, para lo que reclutan a otras mujeres, en el caso de Praxágoras a sus compatriotas de Atenas, mientras que Lisístrata llama a todas las mujeres de la Hélade. Nuevamente, la comicidad radica en la inversión, ya que adquiere papel activo en un espacio público propiamente masculino. De la misma manera que ocurre con Lisístrata, la caracterización de la heroína cómica contrasta rotundamente con la tipificación de los otros personajes femeninos secundarios.

7 Rothwell (1990, p. 83) lo traduce como "one who is active in the agora", mientras que Kanavou (2011, p. 171) como "active in the assembly". Por su parte, Sommerstein (1998, p. 26), citado por Kanavou (2011, p. 171, nota 771), sugiere que significa "women of effective speech". 


\subsection{Personajes inventados de carácter genérico}

En cuanto a los personajes de carácter genérico, se pudo encontrar mayor variedad, 33 en total. Entre ellas, muchas presentan similitudes de acuerdo a su tipo cómico. Asimismo, algunos de estos personajes son dobles, pero su actividad escénica varía, ya que puede que ambos hablen o solo uno o ninguno como en el caso de las hetairas.

Para facilitar el análisis se clasificaron en 5 grupos: diez son mujeres jóvenes $o$ adolescentes -que incluye la variante de las hijas-; diez mujeres maduras -principalmente las esposas-; cuatro ancianas ${ }^{8}$; cinco esclavas o siervas, y nueve mujeres según su profesión, lo que varía dependiendo de cada caso.

También hay grupos de número indefinido como ocurre con las mujeres en los Acarnienses (2000, vv.1003-1005), que aparecen junto a unos niños y a las que Diceópolis encomienda los preparativos de diversos manjares para el banquete. Fuera de ello, no participan en la acción, sino que son figuras que aportan notable variedad al movimiento escénico (Scabuzzo, 2016, p. 349).

Asimismo, en esta categoría se podrían incluir los coros de mujeres, que en total son tres: las mujeres atenienses en Asambleístas, las tesmoforiantes en la obra homónima y el semicoro de ancianas en Lisístrata. No obstante, en el presente trabajo no se profundiza en sus características.

\subsubsection{Mujeres jóvenes o adolescentes}

Las mujeres jóvenes o adolescentes son muy populares en las obras aristofánicas. Se recogen 10 en total. En Asambleístas se encuentran: la Joven (veâviऽ) que participa 15 veces

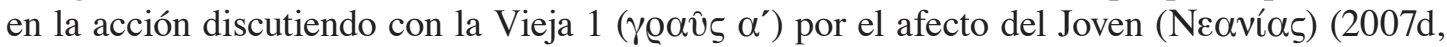
vv. 877-971, 1037-1042) y otras muchachas ( $\mu \varepsilon \varepsilon_{0}(\alpha x \varepsilon \varsigma)$ que acompañan a Bléfiro, esposo de Praxágora, en el banquete final (vv. 1112-1150). Estas últimas son personajes mudos, que funcionan como elemento resolutivo para lograr el esperado final feliz, una variante de la boda, pues ejemplifican el nuevo orden instaurado por la protagonista donde los placeres no se limitan a las viandas.

El humor sexual es una constante en la representación de mujeres jóvenes. En este sentido, es interesante la escena de la Joven (veôvı $)$ que discute con la Vieja 1 por el Joven.

\footnotetext{
La Joven es, sin duda, una muchacha atractiva, cuyos encantos celebra el Joven; desde hace tiempo es el objeto de sus

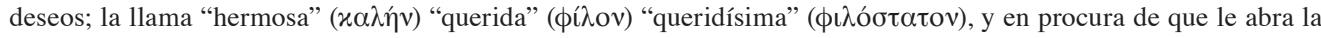
puerta y ceda a sus deseos la cubre con una letanía de hinchados epítetos: "Joya labrada en oro, retoño de Afrodita, abeja de la Musa, pupila de las Gracias, imagen del Placer" (Scabuzzo, 2016, p. 342).
}

No obstante, en la reforma sexual de Praxágora se ha decretado que todos pueden tener relaciones sexuales con quien quieran, pero para evitar la discriminación de las ancianas y las poco agraciadas, se ha dispuesto que quienes son jóvenes y bellos, antes de estar con alguien joven y hermosa como ellos, deberán primero dar satisfacción a alguien viejo o feo. En esto radica la inversión y, por ello, la joven, que normalmente es objeto de deseo, discute violentamente con su rival, hasta que la Joven le argumenta a la Vieja que ella podría ser la madre del muchacho, de modo que con la nueva ley se va a llenar de Edipos la ciudad (v. 1038 ss). Es fundamental la inversión cómica, que Scabuzzo (2016, p. 343) explica de la siguiente manera:

$8 \quad$ No se incluye el Corifeo del semicoro de ancianas presente en Lisístrata. 
En este plano lo que sería natural, es decir que el Joven y la Joven pudieran tener el tan ansiado encuentro, se ve frustrado por la imposición de una norma; el impulso de la Joven y la frescura con que expresa sus deseos están del lado de la phúsis, en tanto la imposición del nuevo orden se inclina a la vertiente del nómos.

La inversión es un mecanismo cómico esencial, no solo en esta escena, sino en toda la obra, puesto que se trata de una comedia de tema femenino que construye su comicidad: las mujeres adquieren un rol masculino, como también ocurre en Lisístrata.

Por su parte, en Lisístrata, hay dos mujeres jóvenes: la beocia (2007e, vv. 86-89) y la corintia (vv. 90-92). Las dos han llegado tarde a la convocatoria de Lisístrata. Son personajes mudos que tiene como finalidad ser objeto de humor sexual por su belleza y juventud. Cleonice resalta de la primera su zona púbica depilada (v. 87) y de la segunda su espléndido aspecto físico (v. 91).

En el caso de las hijas -una variante de las mujeres jóvenes especificada por la relación de parentesco con algún personaje de la obra-, ocurre lo mismo, son objeto del humor

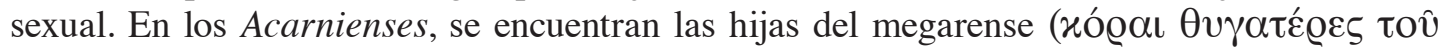

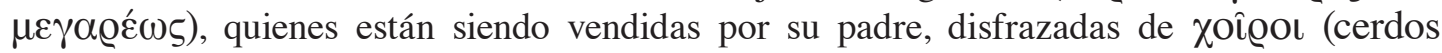
pequeños, lechoncitos), término que en Aristófanes se utiliza de manera metafórica para referirse a los genitales femeninos ${ }^{9}$. Hablan 6 veces, pero 5 son onomatopeyas xoì̀ xoì นoí́ (2000, vv. 735, 780, 801-804). Su padre las mete en un saco con instrucciones de gruñir y chillar como lechones. Esta animalización de las niñas intensifica la comicidad de la escena.

Asimismo, en los Acarnienses (2000, vv. 241-261) se encuentra la joven hija de

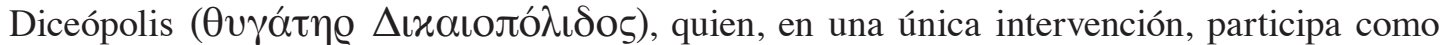
canéfora junto a otros personajes mudos en la procesión ritual dedicada a Fales ${ }^{10}$, durante las Dionisias Rurales. Su aparición "es motivo de alusiones sexuales, expresiones escatológicas y de doble sentido, lo que genera una buena cuota de humor" (Scabuzzo, 2016, p. 261).

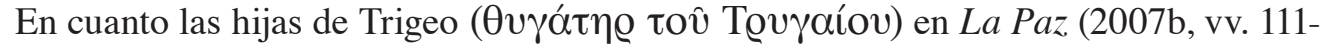
153), no se especifica su número, pero habitualmente se cree que son dos, de las cuales una es muda y la otra trata de disuadir a su padre de no montar al escarabajo estercolero gigante para ir al Olimpo en busca de la Paz. Las ocho intervenciones de la hija de Trigeo mezclan un lenguaje trágico con términos familiares, como $\pi \alpha \pi \tau i ́ \alpha$ pappía "papito" (v. 128) (García Romero, 2016, p. 262). A diferencia de las otras, su comicidad no radica en su caracterización ni en el humor sexual, sino en la incongruencia presente en el uso del lenguaje cotidiano inmerso en la paratragedia.

\subsubsection{Mujeres maduras}

En el caso de las mujeres maduras, estas comúnmente son las esposas de alguno de los personajes masculinos y su edad ronda entre los 30 a 40 años. Por lo general, estas carecen de nombre y se utiliza $\gamma u v \eta ́$ ('mujer') para identificarlas, y si están en grupo, se recurre al uso del

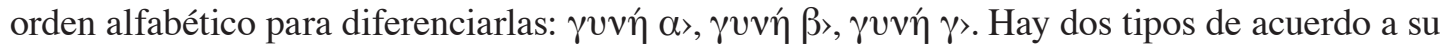
participación en la obra: personaje mudo y dramatis persona en sentido estricto. De las diez

$9 \quad$ Principalmente en los Acarnienses (2000, vv. 739, 764, 767, 768, 769, 771, 773, 778, 781, 788, 792, 794, 795, 800), pero también en la Asambleístas (2007d, v. 724) y en las Tesmoforiantes (2007h, vv. 289, 538, 540).

10 Divinidad de la fecundidad asociada al culto de Dionisos. 


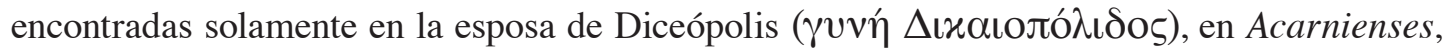
es un personaje mudo y serio, en especial, porque se mantiene dentro del espacio propiamente femenino, en el interior de la casa, cuando sale se asoma brevemente y obedece a su marido para volver a entrar (2000, vv. 241-261). Las otras nueve sí cuentan con comicidad propia.

De hecho, en esa misma obra, se encuentra un personaje singular: la madrina o dama

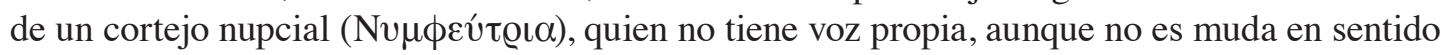
estricto, pues habla a través del protagonista. Ella le dice al oído a Diceópolis, una secreta petición de la novia: esta solicita que mientras su esposo esté en la guerra su falo permanezca con ella, a lo cual Diceópolis accede, porque la novia es mujer y no tiene culpa de la guerra (2000, vv. 1047-1168). Este chiste evidencia un aspecto reiterado en la comicidad de los personajes femeninos: el motivo de la lascivia. La obscena petición cuenta en sí misma con comicidad, gracias al aprosdóketon, es decir, lo 'inesperado' o lo 'imprevisto' que pudo ser esta aseveración para el público. Siguiendo a Scabuzzo (2016, p. 133),

\footnotetext{
La intervención de la Madrina pone de relieve la supremacía de Diceópolis, que da o niega la paz a su arbitrio; por otra parte, completa la visión que tiene Diceópolis sobre los culpables e inocentes en relación con la guerra, esta vez en clave humorística, destacando también el valor otorgado al sexo por encima de otras motivaciones para compartir con otros su paz.
}

Así ocurre también en la trama de Lisístrata. De hecho, en esta obra hay un grupo de cuatro mujeres innominadas seguidoras de Lisístrata, que aparecen en la segunda parte de la comedia (2007e, vv. 728-761), específicamente cuando estas entran en crisis por la huelga de sexo y desean huir de la Acrópolis -donde están recluidas- para unirse con sus maridos. La primera de ellas afirma que debe regresar a su casa porque unas lanas se le están apolillando (v.728); la segunda dice algo parecido sobre un lino (v. 735); la tercera inventa estar embarazada y a punto de dar a luz, para lo cual oculta un broncíneo casco bajo la túnica (v. 750); y finalmente, la cuarta mujer alega que sufre de insomnio por el constante ulular de las lechuzas (v. 760), aves vinculadas a Atenea, diosa titular de la Acrópolis. Estas cuatro mujeres ejemplifican nuevamente el motivo de la lascivia.

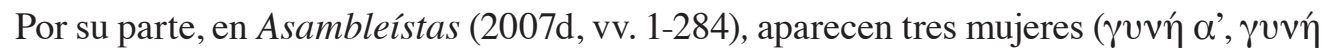
$\beta>, \gamma \cup v \eta \dot{~} \gamma>$ ) que acompañan a Praxágora en la escena inicial, donde discuten sus artimañas para disfrazarse de hombres y entrar en la asamblea: una se broncea todos los días cuando su marido sale, la otra lleva semanas sin depilarse, todas han robado túnicas masculinas, se ponen barbas y practican qué dirán para sonar como varones. Junto a ellas han llegado otras mujeres, personajes mudos, que después, al terminar el prólogo, se reunirán en la orchestra para conformar el Coro de mujeres (Scabuzzo, 2016, p. 348). Nuevamente, el mecanismo imperante es la inversión, la cual se intensifica con el motivo del disfraz en escena, recurso tan utilizado por Aristófanes. Se debe considerar también la comicidad visual de la misma representación, donde los actores -hombres en principio vestidos de mujeres- se disfrazan en escena de varones. Las barbas debían colocarse sobrepuesta en las máscaras de rostro femenino (Scabuzzo, 2016, p. 349). El doble disfraz tendría en el público una indudable vis comica.

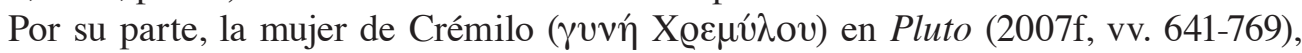
como buen personaje femenino de la comedia, es aficionada al vino (vv. 644-645). Tras haber ido su esposo al templo de Asclepio, dios de la medicina, para devolverle la vista a Pluto, el dios de la riqueza, la mujer espera en su casa las noticias. No obstante, al oír la algarabía de afuera, sale a enterarse de lo ocurrido. En el diálogo que mantiene con Carión, el esclavo, interviene en 33 ocasiones, llena de curiosidad ante el extraordinario hecho, por lo que solicita toda clase 
de datos, aún nimios, y escucha "con gran atención cuando su siervo expone, haciendo, eso sí, comentarios al respecto, unas veces agudos y burlones (vv. 657-658, 684, 700, 713-714) y otras admirativos (vv. 726, 734, 748)" (Mariño Sánchez-Elvira, 2016, p. 345). Su caracterización es potenciada por el esclavo, quien, al narrarle lo ocurrido, le dice, por ejemplo (vv. 737-738): "y antes de que tú bebieras diez copas de vino, ama, Pluto se levantó con vista” (Aristófanes, 2013, p. 592) con lo que recalca así la tipificación de la mujer bebedora de vino, motivo presente también en las ancianas.

\subsubsection{Ancianas}

Las ancianas en Aristófanes carecen de nombre y son personajes sumamente caricaturescos y grotescos. Se resalta su fealdad y lascivia, como ocurre con las tres ancianas

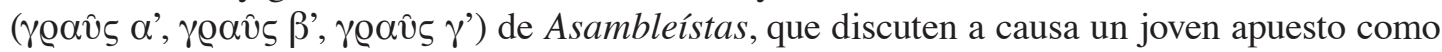
una muestra de la regulación del comercio sexual promulgada por Praxágora. La primera tiene la mayor participación, ya que interviene en la acción 42 veces. Se asoma desde la ventana, exageradamente maquillada y depilada, con un vestido color azafrán, atributo de seducción. Esta expone las ventajas de tener un encuentro sexual con una mujer de su edad, utilizando expresiones escrológicas ${ }^{11}$. Ello contrasta con el uso paródico de la poesía lírica en el intercambio cantado entre esta y la Joven (Scabuzzo, 2016, p. 487). La Vieja 1 lee el decreto de Praxágora para obligar al Joven a tener relaciones sexuales primero con ella que con la Joven, lo cual lleva a esta última a atacarla verbalmente (2007d, v.1041).

Al salir la Vieja 1, ingresa la segunda $\left(\gamma \varrho \alpha v ̂ \varsigma \beta^{\star}\right)$, nuevamente apelando a su derecho por ley. El Joven la describe como un mal peor que el anterior: una "Empusa cubierta de pústulas sanguinolentas" (2007d, v. 1057). Mientras esta lo arrastra a su casa, aparece la tercera anciana ( $\left.\gamma \varrho \alpha \hat{\varsigma} \varsigma \gamma^{6}\right)$, un horror más funesto: "acaso una mona rebozada en albayalde o una vieja que ha resucitado de entre la legión de los muertos" (vv. 1072-1073). Ambas lo acosan y forcejean tirando cada una de un brazo del joven desgraciado con riesgo de descuartizarlo. Estas ancianas tienen menos participación que la primera, pues la segunda habla quince veces (vv. 1049-1111) y la tercera en nueve ocasiones (vv. 1065-1111). La comicidad de la escena radica en el absurdo y en el aprosdóketon, pues cada personaje que aparece para mortificación del joven es aún peor que el anterior y, finalmente, este tiene que admitir que deberá yacer por turno con cada una de ellas.

En la caracterización de las tres destaca la fealdad y la lascivia, lo mismo que sucede con otros que comparten este tipo cómico de la anciana, como es el caso de la una mujer

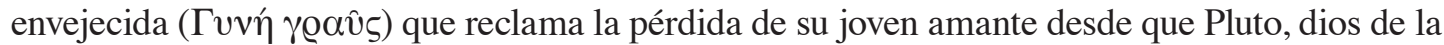
riqueza, ha recobrado la vista (2007f, vv. 959-1096). "La Vieja va caracterizada con una máscara muy maquillada (vv. 1064-1065) y con arrugas (v. 1051), peluca canosa (v. 1043) y vestidos bordados (v. 1199)" (Mariño Sánchez-Elvira, 2016, p. 483), lo cual indica que cuenta con una excelente situación económica, posiblemente debido a su oficio como hetera. La aparición de

11 La escrología ( $\alpha i \sigma \chi \varrho o \lambda o \gamma i ́ \alpha)$ es un término utilizado por Aristóteles en la Ética Nicomáquea (IV 8, 1128a 20) para caracterizar al lenguaje obsceno típico de la comedia antigua y tan utilizado por

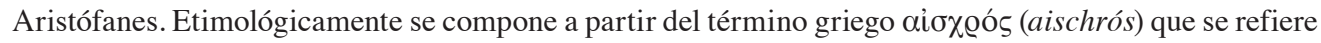
a lo 'feo', lo 'obsceno', lo 'avergonzante', lo ‘infame' y, a grandes rasgos, 'palabras malsonantes'. Véase Liddell y Scott (1989 p. 23). 
este personaje es cómica en sí misma por la tipificación de la anciana, que no se viste acorde a su edad y busca amantes jóvenes. Su jocosidad se intensifica por medio de la utilización de lenguaje trágico.

La principal característica de las ancianas en Aristófanes es la incongruencia: se visten como jóvenes, son adictas al sexo y persiguen jovencitos.

\subsubsection{Esclavas o siervas}

En el caso de las esclavas, se identificaron cinco personajes, que se pueden clasificar en dos tipos de acuerdo con su participación en la obra: personajes mudos y dramatis personae, en sentido estricto, pues participan activamente. Las esclavas mudas únicamente colaboran con personajes activos, cumpliendo las órdenes de estos, por lo que carecen de importancia en la comicidad de la obra. Ello ocurre en las Tesmoforiantes con Manía (Mavía), la sirvienta de Mica, quien es llamada tres veces por su ama: “[...] vamos a buscar unos haces de sarmientos, Manía" (2007h, v. 728), "trae muchos sarmientos, Manía” (v. 739) y "dame el cáliz, Manía [...]” (v. 754). De acuerdo con Esteban Santos (2016, p. 308), el nombre Manía es característico de las esclavas frigias en Atenas, lo cual recalca su caracterización. Sucede lo mismo con Tracia $(\Theta \varrho \hat{\alpha} \tau \tau \alpha)$, la esclava del pariente de Eurípides, quien lo acompaña en un principio, pero después es bruscamente expulsada por este de escena, porque supuestamente no le es permitido a las esclavas participar en las Tesmoforias, festividad religiosa en la que Mnesíloco estaba tratando de infiltrarse (vv. 279-293).

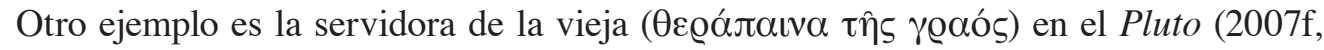
vv. 959-1094), quien entra en escena al lado de su ama con una fuente con víveres -golosinas y dos pasteles- (vv. 995-996, 999), que han sido rechazados por el joven amante. Ella tampoco participa de la acción y su única función es acompañar al personaje de la anciana.

En el caso de las siervas que sí participan en la acción, su caracterización sí cuenta con mecanismos de comicidad. Por ejemplo, en Asambleístas (2007d, vv. 1112-1150), la criada $(\boldsymbol{\theta \varepsilon \rho \alpha ́} \boldsymbol{\pi} \boldsymbol{\alpha} \mathbf{v} \boldsymbol{\alpha})$ de Praxágora utiliza un lenguaje inapropiado a su condición, que bajo los efectos del vino desencadena una verborragia de marcado efecto cómico. Este es otro más de los personajes femeninos que ejemplifican la inversión presente en esta obra.

Por su parte, en las Ranas (2007g, vv. 503-519), se encuentra la criada de Perséfone, cuya función es colaborar con la parodia mítica de Heracles, que en realidad es Hêrakleioxanthías

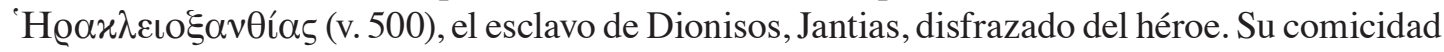
se basa en el ofrecimiento de placeres y múltiples manjares, entre ellos: un buey entero, pasteles, golosinas (vv. 505-507, 510), un guiso de pajaritos (v. 510), rodajas de pescado y "una mezcla de vino dulcísima" (v. 511), con lo cual se recalca la glotonería de Heracles como tópico cómico en

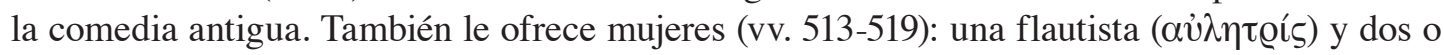

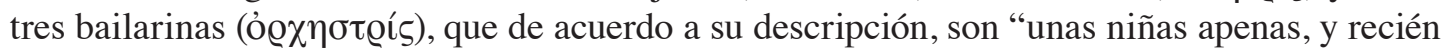

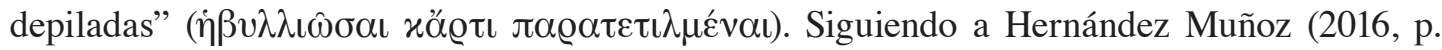
409), esta criada "tiene una función en la obra semejante a las dos posaderas: revelar, como personaje secundario, el verdadero carácter de los protagonistas”, por ello, su participación es activa a través de cuatro intervenciones en diálogo con Hērakleioxanthías (vv. 503-519). 


\subsubsection{Mujeres según su profesión}

Para terminar los personajes inventados, se encuentran las mujeres de acuerdo a su

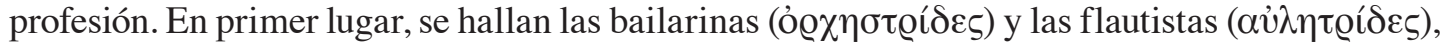

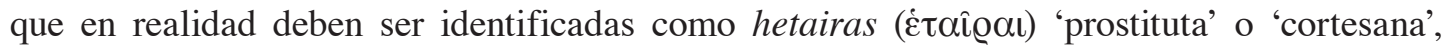
generalmente, de alta condición social en la antigua Grecia. De acuerdo con Pomeroy (2015, p. 89), muchas de ellas, además de tener belleza física, poseían educación intelectual y talentos artísticos, atributos que hacía su compañía más entretenida en las actividades sociales frecuentadas únicamente por hombres. Por ello, muchas heteras desarrollaban dotes musicales y podían ser flautistas o bailarinas, labores que practicaban principalmente en los banquetes. Por tanto, estos personajes en Aristófanes tienen una caracterización ligada a su oficio, pues están tipificadas especialmente como objetos de humor sexual. En general, son personajes mudos, que aparecen en compañía de personajes masculinos importantes.

En el caso de los Acarnienses (2000, vv. 1198-1226), al final, el protagonista, Diceópolis, reaparece en escena junto a dos jóvenes después de ser vencedor en el concurso de bebedores y estas lo ayudan a sostenerse en su estado de ebriedad. Ellas son identificadas como bailarinas y son objeto de expresiones sexuales. En las Tesmoforiantes (2007h, vv. 1160-1200), también aparece una bailarina al final de la obra junto a Eurípides, quien la ha llevado para que seduzca semidesnuda al Arquero escita con una danza persa para así liberar

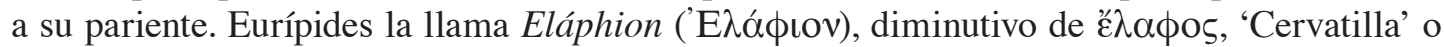
'Gacelita' (v. 1172), típico nombre de prostituta (Esteban Santos, 2016, p. 163).

Finalmente, en las Avispas (2007a, vv. 1326-1380), aparece al final de la obra una flautista ( $\alpha \dot{\jmath} \lambda \eta \tau \varrho i ́ \varsigma)$ junto a Filocleón, el protagonista, quien la hace partícipe de un engaño para su hijo Tiracleón, el cual consistía en hacerlo creer que ella era una antorcha que arde en el ágora.

Naturalmente el intento llevaba consigo la escenificación de una pequeña farsa cómica en la que se discutía, con claras indicaciones a las partes sexuales de la desnuda Flautista, qué era exactamente la hendidura y la negrura que la antorcha humana exhibía entre las piernas, y si la protuberancia posterior que se apreciaba en el desnudo cuerpo de ella era en verdad un nudo de antorcha o más bien un trasero de fémina (López Eire, 2004, p. 166).

Nuevamente, el personaje mudo es objeto de humor sexual, por lo que la comicidad es lograda por los personajes masculinos que la rodean. Probablemente, todos estos personajes fueran representados por heteras reales, pues se requería la desnudez del cuerpo femenino, la cual no se puede lograr por medio del disfraz. En las tres comedias, las hetairas, sean flautistas o bailarinas, son utilizadas como elementos resolutivos, en sustitución del motivo tradicional de la boda propia del final feliz de la comedia.

Después de las heteras, otras mujeres según su oficio son las anfitrionas o dueñas

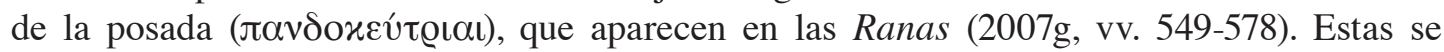
presentan hostiles y atacan a Dionisos disfrazado de Heracles, pues tiene malos recuerdos de la última visita del héroe. Son caracterizadas como mujeres robustas, lo suficiente como para amenazar al dios. Únicamente se revela el nombre parlante de la segunda (v. 549): Platháne

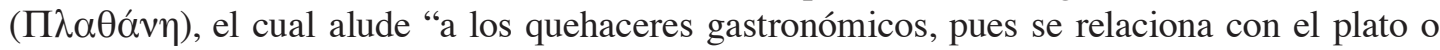
molde ( $\pi \lambda \alpha ́ \theta \alpha v o v$ en griego) donde se amasaban en Grecia los panes y pasteles" (Hernández Muñoz, 2016, p. 409). Su función en la obra es semejante a la de la criada de Perséfone: colaborar con la parodia mítica. 


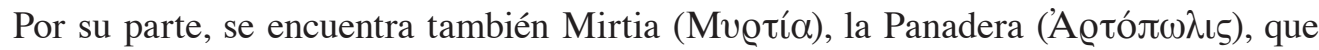
en las Avispas (2007a, vv. 1388-1416) reclama gritando a Filocleón la pérdida de su mercancía. En la discusión con el personaje masculino, esta interviene en cinco ocasiones y su nombre es mencionado por ella misma cuando se presenta como hija de Anquilión y Sosastre (vv. 1396-1397). La comicidad de este personaje radica en la tipificación del estereotipo social de la mujer del mercado que a gritos exige el pago de sus productos ${ }^{12}$, lo mismo que sucede con las posaderas de las Ranas.

Finalmente, se encuentran las mujeres con profesiones propias del campo masculino y por ende, su comicidad radica en la inversión. En Lisístrata hay un personaje que aparece caracterizado como una escita, una mujer bárbara que tendría a su cargo el orden civil, a modo de un policía, como el Arquero escita en Tesmoforiantes. Se trata de un personaje mudo, que llega tarde a la convocatoria de Lisístrata, entra un tanto distraída y trae un escudo que utiliza durante el juramento (2007e, vv. 184-186). Por supuesto, en Atenas no existían «arqueras» escitas, pues era una profesión propiamente masculina, dada a los esclavos públicos, principalmente aquellos procedentes de Escitia, pueblo propiamente guerrero. Sin embargo, siguiendo a Macía Aparicio (Aristófanes, 2007e, p. 37, nota 17), la presencia de este personaje femenino pretende dar un carácter oficial a acción de las mujeres, que en apariencia celebran una Asamblea en toda regla.

Por otra parte, en Asambleístas (2007d, vv. 834-852) hay una mujer heraldo, que

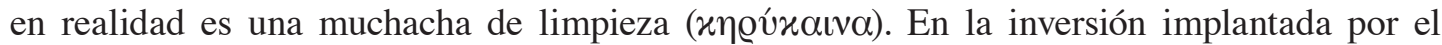
liderazgo político de Praxágora, se elige a una mujer con buena voz para ejecutar la función de heraldo (v. 713), oficio propiamente masculino, como aparece reiteradamente en esta obra (vv. 30, 684, 821 y 834). Si bien es una sierva, se inserta en un ámbito propiamente masculino. Al igual que la policía escita, su presencia ejemplifica el nuevo orden político y, por ende, su comicidad radica en la inversión, característica presente a lo largo de toda la obra.

\subsection{Personificaciones de carácter alegórico}

Finalmente, hay siete personificaciones femeninas de carácter alegórico: Eirene

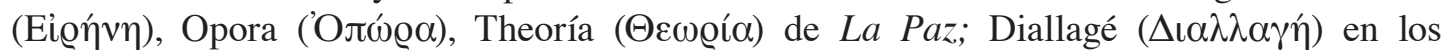

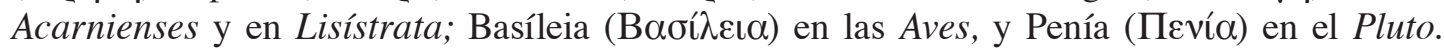
Todas estas personificaciones son mujeres jóvenes y hermosas a excepción de Penía.

\subsubsection{Eirene, Opora y Theoría en La Paz}

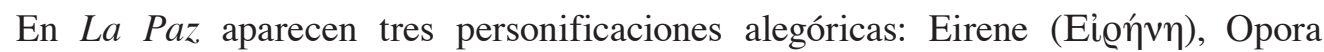

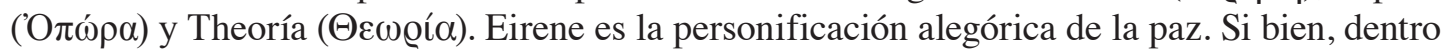
de la mitología griega, Eirene pertenece a la tríada de las Horas -junto a sus hermanas Dike y Eunomía, "la Justicia" y "la Buena Ley"- hijas de Temis y Zeus, hermanas de las Moiras; en Aristófanes no se hace alusión a su genealogía divina y aparece acompañada de otras personificaciones: Opora y Theoría. 'O $\pi \omega ́ \rho \alpha$ significa 'fin del verano', 'principio del otoño',

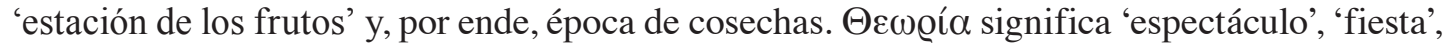
‘certámenes', eso sí, todo de carácter religioso.

12 Este estereotipo social también es mencionado en el Pluto (2007f, vv. 426-427).

Doi: https://doi.org/10.15517/rfl.v46iEspecial.41632 / URL: https://revistas.ucr.ac.cr/index.php/filyling/index 
Aunque Aristófanes no esté imitando el personaje mítico de Eirene en sí mismo, sí se observan ciertas semejanzas en función, pues las Horas regían tanto los ritmos agrarios como los cívicos, es decir, tenían una doble acepción: natural y política. En efecto, ello se ve reflejado en esta tríada de invención aristofánica.

En la obra, el protagonista Trigeo, un viñador ático, víctima de la guerra que acaece sobre los helenos, sube al Olimpo sobre un escarabajo estercolero para preguntarle a Zeus qué pretende hacer con todos los griegos. Cuando llega allí, encuentra el lugar abandonado y solo a Hermes, que está custodiando los bienes del palacio. Este le cuenta que los dioses se han mudado muy lejos, "debajo mismamente del cascarón del cielo" (Aristófanes, 2011, p. 283). El estado de conflicto se encuentra también en el mismo Olimpo, donde ahora se instaló Pólemo, personificación de la guerra, quien encerró a Eirene en una cueva. Trigeo junto a los labradores de toda Grecia logra liberarla.

El carácter agrario dentro de la semiosis del texto es bastante evidente, Eirene es llamada (2007b, v. 520): “¡Oh señora que nos regalas la vid!”, y ella se presenta como patrona de los labradores y, precisamente, la diosa que respalda el nuevo orden basado en la agricultura. De allí que se trate de un personaje serio y silencioso, no mudo, pues habla a través de Hermes. En la obra, se excusa el silencio de Eirene por su enfado contra los hombres que han causado la guerra, que, según expone Hermes, comenzó con la calamidad del famoso escultor ateniense, Fidias, al ser desterrado de Atenas por malversación de fondos.

La mención de Fidias no es casual, pues el corifeo señala en el verso 617 que la diosa “[...] era muy guapa porque era pariente de aquél”. No se sabe a ciencia cierta si Fidias elaboró una escultura de la diosa Eirene, pero por indicios se puede suponer que la escultura utilizada en la obra para representar a este personaje se asemejaba al estilo propio del escultor. El uso de esculturas en lugar de actores era habitual en el caso de divinidades relevantes, como se observó con Iris.

Eirene es un personaje que carece de comicidad por su misma importancia en la obra, lo cual no sucede con su cortejo. Eirene concede a Opora como esposa a Trigeo y otorga a Theoría al Consejo. En ambas figuras se encuentran algunos elementos de comicidad, especialmente en relación con el humor sexual, tanto en la unión matrimonial como en la orgía del Consejo. Alrededor de ambas se hallan expresiones escrológicas, pero en especial con la figura de Theoría, quien es objeto de la orgía, la cual es descrita por Trigeo por medio de una metáfora gimnástica (2007b, vv. 894-906).

Tanto Opora como Theoría son personajes mudos que tienen una fuerte carga sexual, potenciada por el lenguaje escrológico, el cual, a su vez, está ligado también al ritual, factor propio de la comedia. López Eire (2004, p. 163) explica que

Esa risa ligada a la obscenidad, la escrología, la escatología, la borrachera, la invectiva y el escarnio era, en efecto, una «risa ritual», permitida como parte de la fiesta de dioses de la fecundidad y por tanto amantes de la risa, que se asociaba a determinados y específicos ritos [...].

Precisamente, en esta obra, la comicidad final busca esta "risa ritual"13, lograda con el humor sexual presente en las expresiones escrológicas de los personajes masculinos. No obstante, el silencio femenino no es tan inocente como parece, ya que se trata de un silencio ritual que se ve contrapuesto a la obscenidad utilizada para aumentar la fuerza genésica.

13 Para más información sobre la risa ritual, consúltese el trabajo de López Eire (2004). 
Recuérdese que la comedia es un rito dedicado a Dionisos, dios de la fertilidad. Finalmente, la obra termina con el casamiento de Trigeo y Opora, motivo propio para lograr el final feliz de la comedia.

\subsubsection{Diallagé en Acarnienses y Lisístrata}

Diallagé es una personificación presente en Acarnienses (2000, vv. 988-999) y en Lisístrata (2007e, vv. 1112-1156). A diferencia de los demás personajes de este tipo, no se trata de una divinidad, sino que es una antropomorfización del concepto abstracto $\delta 1 \alpha \lambda \lambda \alpha \gamma \eta$, entendido como un "cambio de enemistad en amistad", "reconciliación" o "paz" (Pabón, 2005, p. 140). En ambas obras, se presenta como una mujer joven y hermosa. En Acarnienses (2000, vv. 988-999), su aparición ocasiona el apetito sexual del coro, lo cual conduce a diversas alusiones sexuales en una metáfora de carácter agrario (vv. 995-999), labores que únicamente pueden realizarse en un estado de paz. "Además de reforzar el contraste entre el estado de guerra y la paz, este personaje da lugar al humor sexual que, expresado en lenguaje indirecto, apela a la complicidad del espectador con el consiguiente efecto cómico" (Scabuzzo, 2016, p. 431).

También en Lisístrata (2007e, vv. 1112-1156), Diallagé funciona como una alegoría de la conciliación entre los espartanos y los atenienses, en este caso, debida a la huelga de sexo de las mujeres. La joven es entregada por Lisístrata a los ansiosos hombres, que halagan distintas partes de su cuerpo desnudo. Posiblemente, ambas estuviesen representadas por una joven desnuda, una hetera, al igual que Theoría en La paz. El motivo de la orgía se utiliza en estas obras como una variante del final feliz de la comedia.

\subsubsection{Basíleia en Las Aves}

En las Aves, al hablar de Iris, aparece una deidad personificada: $\beta \alpha \sigma i ́ \lambda \varepsilon ı \alpha$ (Basíleia) ("reina"). En el marco de la obra aristofánica, este nombre es traducido habitualmente como "Soberanía", así lo hacen Baráibar y Zumárraga (Aristófanes, 1954), Rodríguez Adrados (Aristófanes, 1990), Macía Aparicio (Aristófanes, 2007c), mientras que Garibay K. (Aristófanes, 1986) emplea "Regina". Este personaje se utiliza como una personificación del "poder real" ( $\beta \alpha \sigma \imath \lambda \varepsilon i ́ \alpha)$ de Zeus, lo cual se hace evidente cuando Prometeo revela su identidad (vv. 1537-1541): "Una chica preciosa. Ella administra el rayo de Zeus y todos sus demás atributos: buen consejo, leyes justas, prudencia, arsenales, insultos, colacretas, trióbolos...”. No se establece una relación de parentesco entre esta diosa aristofánica y Zeus, pero Anderson y Dix (2007, p. 322) sugieren que podría tratarse del kýrios de Basíleia, es decir, el tutor oficial legalmente hablando.

La joven aparece como elemento resolutivo del conflicto surgido por la fundación de la Nephelokokkugía, la "ciudad de las nubes y los cucos", al haber obstruido el paso del humo de los sacrificios (2007c, vv. 1515-24). Ante esta situación, Prometeo va en busca de Pistétero para avisarle que Zeus enviará una embajada y le aconseja solicitar en matrimonio a Basíleia a cambio de la restitución del libre tránsito entre hombres y dioses (vv. 1531-1536).

Basíleia es un personaje mudo que no participa activamente en la acción. Su nombre se menciona seis veces (vv. 1536, 1537, 1634, 1687, 1730, 1753), pero aparece hasta el casamiento, motivo característico del final de la comedia. El matrimonio con Pistétero marcaría el establecimiento del nuevo orden aristofánico de carácter utópico. Se trata de un final similar al presente en $\mathrm{La} \mathrm{Paz}$, con el matrimonio entre Trigeo y Opora. 


\subsubsection{Penía en Pluto}

Finalmente, Penía es una personificación deificada de la pobreza, la miseria y la escasez, antítesis de Pluto, dios de la riqueza. Ella será la mayor afectada cuando este obtenga la vista con ayuda de Crémilo, el héroe cómico. En principio, el protagonista deseaba que la riqueza fuese justa, es decir, que los virtuosos fueran ricos y los malvados pobres (2007f, vv. 93-98, 490-491, 494-496). No obstante, Crémilo hace creer a Penía que sería una definitiva eliminación de la pobreza, por lo que en esta utópica situación se necesita su destierro definitivo de la Hélade (vv.460-465).

Penía participa en la acción en 34 ocasiones (2007f, vv. 418-486, 507-609) principalmente en el agón contra Crémilo, donde ella argumenta las ventajas de su presencia: gracias a ella hay necesidad de trabajar para ganarse el sustento $\mathrm{y}$, por ende, hay productos para el consumo de otros (vv. 507-609); hace mejores a los hombres en cuerpo y mente (v. 558), pues ayuda a evitar enfermedades como la indigestión al comer demasiado (vv. 559-561), y solo en su presencia los políticos son íntegros (vv. 567-570). Ante la elocuencia de Penía, Crémilo pasa a los insultos y maldiciones, hasta que finalmente expulsa a Penía violentamente de escena (vv. 610-612), recurso utilizado también con el personaje de Iris en las Aves (2007c, vv. 1258-1261). El contraste entre la seriedad y la elocuencia de Penía en contraposición a la charlatanería y el lenguaje escrológico de los personajes masculinos desempeña un papel fundamental en la comicidad de la escena.

Por otra parte, todas las personificaciones anteriores son mujeres jóvenes y hermosas a excepción de Penía (Пعvía), que está más cercana a la caracterización de la anciana, con variaciones, pues presenta una máscara trágica, lívida (v. 422) y se asemeja a una Erinis sacada de alguna tragedia, por su mirada delirante y trágica (v. 424). Asimismo, la manera de revelar su identidad (v. 437) recuerda a la anagnórisis trágica (Mariño Sánchez-Elvira, 2016, p. 388). Por ello, el mecanismo cómico imperante en la caracterización de Penía es la paratragedia, tanto en su lenguaje, enriquecido con citas trágicas, como en su misma imagen y seriedad.

\section{Conclusiones}

Se identificaron 48 personajes femeninos en Aristófanes, se clasificaron y se expuso concisamente la invención de cada personaje, su función en la obra y su comicidad. De acuerdo a su invención, solamente un $2 \%$ imita a un personaje mítico; $14,5 \%$ son inventados con caracterización específica, generalmente, con nombres parlantes; $69 \%$ son de carácter genérico basados en un tipo cómico, como las jovencitas, las ancianas, las esclavas, etc., y finalmente, un $14,5 \%$ de los personajes femeninos son creados por medio de personificaciones, de los cuales 5 por deificación y 2 por antropomorfización.

En cuanto a la comicidad, se encontró que generalmente se utiliza la inversión, el contraste, la incongruencia cómica y el humor sexual para generar el efecto cómico deseado. No obstante, lo que más impera es el humor sexual, tanto en boca de personajes femeninos (chistes, doble sentido, metáforas, etc.), como por ser objeto de este. El lenguaje escrológico de muchos personajes masculinos está dirigido contra jóvenes hermosas, sean personificaciones o personajes inventados con caracterización genérica. Asimismo, a ello hay que añadir el uso de motivos cómicos recurrentes para representar a las mujeres de mayor edad, sean maduras o ancianas, como adictas al sexo o al vino. 
Por otra parte, las funciones de los personajes femeninos son diversas. Se encontraron dos heroínas cómicas, Lisístrata y Praxágoras, las cuales tienen características muy particulares y marcadas por su seriedad; personajes de comicidad propia, como Cleonica o Mirrina; otros que son objeto de la comicidad de interlocutores tanto masculinos como femeninos, por medio de bromas o lenguaje escrológico; figuras de relleno que enriquecen el movimiento escénico y que, por lo general, son mudas y serias; también están aquellos personajes que colaboran con la caracterización de otros con papeles más relevantes en la obra, y, finalmente, la utilización de personajes femeninos como elemento resolutivo para lograr el final feliz tan esperado en la comedia. En esta última, se distinguió varios tipos: el principal es el motivo tradicional de la boda, que aparece en $L a$ paz y en Las Aves, pero hay variantes, como la unión con heteras presente en las Avispas, Asambleístas y Tesmoforiantes, o el motivo de la orgía hallado en Lisístrata, en Acarnienses y en La paz.

Es importante aclarar que las obras de Aristófanes se presentaban en un ámbito ritual propio del culto a la fertilidad, por lo que no es de extrañar que impere el humor sexual y concluya con la unión de dos o más personajes, pues eran representadas en un ámbito religioso dedicado al culto de Dionisos.

Este análisis no fue enfocado desde la teoría de género ni desde los estudios de la mujer, pues en realidad tenía como objetivo general brindar una propuesta de clasificación de los personajes femeninos, tomando en consideración aquellos con papeles secundarios y mínimos en acción, generalmente obviados en trabajos de este tipo; considerando los mecanismos de invención de cada, su función en la obra y algunos aspectos de su comicidad.

\section{Bibliografía}

Anderson, C. y Dix, T. K. (2007). Prometheus and the Basileia in Aristophanes' Birds. The Classical Journal, 102(4), 321-327.

Aristófanes. (1954). Las aves. En Aristófanes. Obras completas (F. Baráibar y Zumárraga, trad.) (pp. 371-442). Buenos Aires: Ateneo Editorial.

Aristófanes. (1986). Las aves. En Aristófanes. Las once comedias (Á. Garibay, trad.) (pp. 163197). México: Editorial Porrúa.

Aristófanes. (1990). Las aves. En Las avispas. La paz. Las aves. Lisístrata (F. Rodríguez Adrados, trad.) (pp. 189-261). Madrid: Cátedra.

Aristófanes. (2000). Acarnienses. En Comedias I: Los acarnienses. Los caballeros (L. GilFernández, trad.) (pp. 71-195). Madrid: Editorial Gredos.

Aristófanes. (2007a). Las avispas. En Comedias II. (L. Macía Aparicio, trad.) (pp. 119-220). Madrid: Editorial Gredos.

Aristófanes. (2007b). La Paz. En Comedias II. (L. Macía Aparicio, trad.) (pp. 221-323). Madrid: Editorial Gredos.

Aristófanes. (2007c). Los pájaros. En Comedias II. (L. Macía Aparicio, trad.) (pp. 325-454). Madrid: Editorial Gredos.

Aristófanes. (2007d). La asamblea de mujeres. En Comedias III (L. Macía-Aparicio, trad.) (pp. 319-409). Madrid: Editorial Gredos. 
Aristófanes. (2007e). Lisístrata. En Comedias III (L. Macía-Aparicio, trad.) (pp. 9-104). Madrid: Editorial Gredos.

Aristófanes. (2007f). Pluto. En Comedias III (L. Macía-Aparicio, trad.) (pp. 413-510). Madrid: Editorial Gredos.

Aristófanes. (2007g). Ranas. En Comedias III (L. Macía-Aparicio, trad.) (pp. 201-316). Madrid: Editorial Gredos.

Aristófanes. (2007h). Tesmoforiantes. En Comedias III (L. Macía-Aparicio, trad.) (pp. 107197). Madrid: Editorial Gredos.

Aristófanes. (2011). La Paz. En Comedias II: Las nubes - Las avispas - La paz - Las aves. (L. Gil-Fernández, trad.) (pp. 249-364). Madrid: Editorial Gredos.

Aristófanes. (2013). Pluto. En Comedias III: Lisístrata - Las Tesmoforiantes - Las Ranas - Las Asambleístas - Pluto (L. Gil-Fernández, trad.) (pp. 249-364). Madrid: Editorial Gredos.

Aristóteles. (1985). Ética nicomáquea. Ética eudemia. (J. Pallí Bonet, trad.). Madrid: Editorial Gredos.

Esteban Santos, A. (2016). Personajes en las Tesmoforias de Aristófanes. En C. González Vázquez (Ed.), Diccionario de Personajes de la Comedia Antigua (pp. 163- 164, 308). Zaragoza: Libros Pórtico.

Eurípides. (1985). Heracles. En J. L. Calvo Martínez (Ed.), Eurípides Tragedias II (pp. 73-136). Madrid: Gredos.

García Romero, F. (2016). Personajes en Paz de Aristófanes. En C. González Vázquez (Ed.), Diccionario de Personajes de la Comedia Antigua (pp. 261-262). Zaragoza: Libros Pórtico.

Gil, L. (1993). La comicidad en Aristófanes. Cuadernos de Filología Clásica. Estudios griegos e indoeuropeos, 3, 23-39.

Gil, L. (2012). Aristófanes. Madrid: Editorial Gredos.

González Vázquez, C. (Ed.). (2016). Diccionario de Personajes de la Comedia Antigua. Zaragoza: Libros Pórtico.

Hernández Muñoz, F. G. (2016). Personajes en Lisístrata y Las Ranas de Aristófanes. En C. González Vázquez (Ed.), Diccionario de Personajes de la Comedia Antigua (pp. 85, 285, 331-332, 409). Zaragoza, Libros Pórtico.

Hesíodo. (1978). Obras y fragmentos. (A. Pérez Jiménez, y A. Martínez Díez, trad.). Madrid: Editorial Gredos.

Homero. (1991). La Ilíada. (Emilio Crespo, trad.). Madrid: Gredos.

Hughes, A. (2012). Performing Greek Comedy. Cambridge: Cambridge University Press.

Kanavou, N. (2011). Aristophanes' Comedy of Names. Berlin: Water de Gryte.

Liddell, H. G. y Scott, R. (1989). An Intermediate Greek-English Lexicon: Founded Upon the Seventh Edition of Liddell and Scott's Greek-English. Oxford: Clarendon Press.

Liddell, H. G. y Scott, R. (1996). A Greek-English Lexicon with a revised supplement. Oxford: Clarendon Press. 
López Eire, A. (2004). Risa, ritual y poesía. Cuadernos del CEMYR, 12(15), 155-209.

López Férez, J. A. (2006). Una lectura de la Lisístrata de Aristófanes. Synthesis (La Plata), $13,11-48$.

Mariño Sánchez-Elvira, R. (2016). Personajes en el Pluto de Aristófanes. En C. González Vázquez (Ed.), Diccionario de Personajes de la Comedia Antigua (pp. 345-346, 388390, 483-485). Zaragoza: Libros Pórtico.

Pabón, J. M. (2005). Diccionario Manual Griego. Barcelona: VOX.

Pomeroy, S. B. (2015). Goddesses, Whores, Wives \& Slaves. London: Penguin Random House UK.

Retórica a Herenio. (1997). (S. Núñez, Trad.) Madrid: Editorial Gredos.

Rothwell, K. (1990). Politics and Persuasion in Aristophanes' Ecclesiazusae. Leiden: Brill.

Scabuzzo, S. (2016). Personajes en Acarnienses y Asambleístas de Aristófanes. En C. González Vázquez (Ed.), Diccionario de Personajes de la Comedia Antigua (pp. 133, 260-261, 342-349, 431, 486-488). Zaragoza: Libros Pórtico.

Yarza, F. S. (Ed.). (1998). Diccionario Griego- Español. Barcelona: Editorial Ramón Sopena.

Zimmermann, B. (2014). Aristophanes. En M. Fontaine, y A. C. Scafuro (Eds.), The Oxford Handbook of Greek and Roman Comedy (pp. 132-159). New York: Oxford University Press. 